\title{
Perceived Usefulness of Jitsi Meet in an EFL Classroom
}

\author{
Like R. Octaberlina ${ }^{1 *}$, Afif I. Muslimin ${ }^{2}$ \\ ${ }^{1}$ Universitas Islam Negeri Malang, Indonesia; ${ }^{2}$ Universitas Islam Negeri Mataram, Indonesia, \\ 2Universitas Negeri Malang, Indonesia
}

\begin{abstract}
Particularly in the field of education, technological developments are both quick and vast. Technology such as video conference utilization is a requirement that must be fulfilled. The goals of this study were to: (1) investigate students' perceptions of Jitsi Meet as an effective educational tool; and (2) investigate the impact of Jitsi Meet on EFL learners' perceptions of it as an aid to teaching. The qualitative technique was employed in this study, and the TAM (Technology Acceptance Model) by Davis (1989) served as the theoretical foundation. This research used three instruments: the researcher, an online questionnaire, and interviews. The findings of this study revealed that students had a good attitude about the usage of Jitsi Meet as a learning tool in the EFL classroom, particularly for virtual learning. Jitsi Meet is the ideal option for use as a meeting or discussion tool in and out of the classroom. This research also indicated that some students are willing to utilize Jitsi Meet in the upcoming by its time and location flexibility, minimum internet bandwidth requirements, and multitasking capabilities. However, there are other factors to consider, such as internet reliability and the development of additional learning functions.
\end{abstract}

Keywords: Jitsi Meet, EFL Classroom, Learning Tool, Students' Perception, Video Conferencing

\section{INTRODUCTION}

Technology has recently gained significance in the education industry at present, therefore educators should use and take use of the numerous accessible technological resources to better fit their classroom demands. The advancement of technology in the EFL classroom is extremely significant nowadays. The use of appropriate technology in the classroom that is wellimplemented in the media for teaching will readily engage and motivate learners (Genc Ilter, 2009)

Teachers in the field of online education and training are increasingly looking for media or technologies to help them educate more effectively. To aid teachers in delivering explanations relevant to the topic, the usage of media is vital. That rationale underlines the rapid technical growth of learning media, particularly in the learning media system. Synchronous and asynchronous learning systems are the two types of learning systems used in media for technical purposes. Karal (Karal et al., 2011) stated in the learning system, a clear separation between synchronous and asynchronous frameworks was specified. The synchronous design enables instructors and learners to communicate in real time, even if they are in separate locations. The asynchronous design is represented by e-learning models in which students and teachers are not required to communicate in real time and where the learner is given the opportunity to acquire information at his or her own pace.

Additionally, because of the advantages of real-time learning, teachers are seeking for ways to communicate with students in a synchronous manner. Karal (2011) noted that in the virtual classroom, synchronous learning is an excellent way to encourage creativity and active class involvement, and teachers benefit from immediate assessment and feedback. Asynchronous learning, on the other hand, may diminish meaningful contact and student interest. There are a number of different techniques that facilitate synchronous learning, including video conferences, web seminars (also known as webinars), and so on (Basko \& Hartman, 2017) Jitsi Meet is a popular video-conferencing platform that allows users to meet without needing to first have an account. End-to-end encryption is also used to protect the connection and user data.

In the previous study, Al-Maroof \& Al-Emran (2018) Using the Technology Acceptance Model as the theoretical framework and the PLS-SEM methodology, this study investigates the factors that influenced students' acceptance of the usage of Google Classroom in their learning process. 337 undergraduate students from Al Buraimi University College (BUC) in Oman took part in the study. The data for this study was collected via a questionnaire. The study's findings show that both of TAM's primary key keywords (PU and PEOU) have a favorable impact on university students' actual use of Google Classroom. Second, Sefrika and Alawiah (2020) did their study, the researchers used TAM theory and quantitative research to investigate students' acceptance of video conferencing as a distant learning medium. A total of 200 students took part in the study, all of them utilized Vicon (videoconferencing) during their class.

Corresponding Author e-mail: sumarmi.fis@um.ac.id https://orcid.org/0000-0002-0516-6427

How to cite this article: Octaberlina, LR. Muslimin, Al (2022). Perceived Usefulness of Jitsi Meet in an EFL Classroom. Pegem Journal of Education and Instruction, Vol. 12, No. 1, 2022, 177-181

Source of support: Nil

Conflict of interest: None.

DOI: $10.47750 /$ pegegog.12.01.17

Received: 10.06.2021

Accepted: 02.12.2021 Publication: 01.01.2022 
The findings reveal that $69.80 \%$ of the participants think that electronic learning aids are easy to use, and that $97.45 \%$ of the participants agree that this application is fairly good in terms of the benefits they receive. Students may accept video conferencing as an e-learning medium during distance learning, according to 72.69 percent of the participants.

Third, Blasco and Virto (2020) conducted research used TAM theory, PLS-SEM, and pre-test data to investigate factors that influence students' perceptions of Google Meet's performance as an e-learning videoconferencing platform. A questionnaire was utilized to collect data from 66 individuals in their study. The findings of their research, which show that each element has a link and influences one another. The relationship between intent to use and fun was the most significant element. This research also shown that students are engaged with the content and like the fun and relevance of the materials.

\section{Method}

This study used qualitative research methods. In order to obtain a better understanding of the phenomena, the researcher utilized a case study. TAM theory by Davis (1989) also lends validity to this research. The researcher has selected 27 sixthsemester students from the English Literature Department, Faculty of Humanities, Maulana Malik Ibrahim State Islamic University, Malang, to serve as questionnaire correspondents. The researcher picked this topic as a result of their frequent usage of Jitsi Meet as a virtual learning tool in EFL courses. They utilized it to have simultaneous learning sessions with their lecturers via video conferencing. From the entire number of participants, 6 participants were enrolled as interviewee to share their thoughts and ideas about using Jitsi Meet in their learning activity. They were picked due to the uniqueness of the responses provided on the questionnaire. The researcher also determined to utilize two instruments to complement the primary instrument in the form of a questionnaire, which was followed by a depth-interview to get additional data.

After gathering data via an online questionnaire and interview, the data was evaluated using a variety of methods. Three methods were employed in this study based on Miles and Huberman (1994), These were data reduction, data presentation, and drawing/verifying conclusions. Following the completion of the questionnaire and the interviewing of the correspondents, both data must be evaluated in a number of stages. The researcher utilized technique triangulation in this investigation. This is done by conducting interviews to verify the responses of the respondents on the questionnaire. This step is critical in order to minimize data misinterpretation and to offer extra supporting data for this investigation.

\section{FINDINGS AND DISCUSSION}

\section{Perceived of Usefulness (PU)}

According to several students, Jitsi Meet is useful as a medium for remote learning. It is due of its characteristics that make it easier for learners to fulfill their wants. On the other side, as seen by the findings in the table, more than half of those respondents opted to be neutral. As a result of the epidemic, they must respond with something new, such as a shift from traditional to digital learning. The adoption of creative and appropriate approaches is important in increasing students' academic motivation during remote learning (Genc Ilter, 2009; Park \& Bonk, 2007).

As a result of its characteristics, the usage of Jitsi Meet during distance learning may enable strong engagement, feedback, and direct reinforcement among students and lecturers. Which of these elements can have an impact on students' learning outcomes? Using this feature might also inspire less interested students to express themselves in the distance learning (Basko \& Hartman, 2017; Karal et al., 2011)

\section{Perceived Ease of Use (PEOU)}

Jitsi Meet is simple to use, even for inexperienced users. Learners do not need to create an account in Jitsi Meet to participate in the class; they only need to click on the link supplied by the instructor and join the class using their browser on a smartphone or computer. It assists students in meeting their learning needs, including as clear communication, the substitution of face-to-face engagement in offline classes, and immediate feedback from classmates and instructors.

However, there were numerous things, both internal and external, that influenced the usage of Jitsi Meet in terms of its ease of use or usefulness for both students and instructors. Poor internet connections, low device specifications, and server latency all contribute to the demise of distant learning. As a result, the lecturer should have alternative choices to anticipate

Table 1: Perceived of Usefulness

\begin{tabular}{|c|c|c|c|c|c|}
\hline Aspects & $\begin{array}{l}S A \\
(\%)\end{array}$ & $\begin{array}{l}A \\
(\%)\end{array}$ & $\begin{array}{l}N \\
(\%)\end{array}$ & $\begin{array}{l}D \\
(\%)\end{array}$ & $\begin{array}{l}S D \\
(\%)\end{array}$ \\
\hline Jitsi Meet allows the students engage with peers and lecturers at the same time. & $22.2 \%$ & $48.1 \%$ & $25.9 \%$ & $3.7 \%$ & $0 \%$ \\
\hline Jitsi Meet helps the students accomplish their learning. & $14.8 \%$ & $48.1 \%$ & $33.3 \%$ & $3.7 \%$ & $0 \%$ \\
\hline Jitsi Meet enhances learning effectiveness for the students. & $3.7 \%$ & $37 \%$ & $55.6 \%$ & $3.7 \%$ & $0 \%$ \\
\hline $\begin{array}{l}\text { The students' can improve their performance in the learning process by using } \\
\text { Jitsi Meet. }\end{array}$ & $0 \%$ & $29.6 \%$ & $55.6 \%$ & $11.1 \%$ & $3.7 \%$ \\
\hline
\end{tabular}


events like these. This is critical since the simplicity of use will influence the intensity of usage and the user's attitude. Some issues that have arisen have the potential to reduce students' motivation to learn.

As a result, using Jitsi Meet provides simplicity by eliminating the requirement to first register an account in order to join the class. Learners and instructors are not required to attend lessons at a specific location. However, numerous factors, such as the stability of the internet connection and the availability of appropriate equipment, impact the effectiveness of Jitsi Meet lessons that is in line with Martin (2005).

\section{User Attitude (UA)}

The perceived ease of use (PEOU) has a major impact on user attitude (UA) (Masrom, 2007). Jitsi Meet is thought to be useful by the majority of correspondents. It is backed by tools such as share screen, microphone, and chat box, which allow people to connect via text. Face-to-face video also aids in interpreting the gestures of others, particularly the speaker. During a pandemic, this is a good approach to do distant learning. When utilizing $\mathrm{j}$ as a learning tool, however, there are some difficulties to consider, including an unreliable internet connection and an unsupported device. As we all know, not every student has access to the same internet connection or gadget.

As a result, the instructor can conduct the class synchronously during distance learning using Jitsi Meet
UIN Malang, which is an alternative to many other video conferences. Some learners were also enthusiastic about the app. When instructors utilize Jitsi Meet, they must keep in mind that it is simply a tool for conducting learning; the strategies employed in delivering information and approaching learners are the most important factors in ensuring that the learning process is effective.

\section{Intense of Use (IU)}

Some people who used this app will use it in the future again. Some said they would use the program again for both class and non-class uses, such as webinars, meetings, study groups, and just for communicating with colleagues (Basko \& Hartman, 2017).

However, there are certain factors to consider when it comes to student boredom in remote learning. During videoconferencing, the most difficult issue is students' boredom. This program is only a tool for conducting learning; the methods used to convey material and approaches to students are the most important factors in ensuring that the learning process is effective. The more diverse the tactics and approaches used, the less bored the pupils will become. In light of this, it is important to increase Jitsi Meet's features and quality.

As a result, Jitsi Meet may be used as a substitute for traditional media in conducting lessons or meetings both

Table 2: Perceived Ease of Use

\begin{tabular}{|c|c|c|c|c|c|}
\hline Aspects & $\begin{array}{l}S A \\
(\%)\end{array}$ & $\begin{array}{l}A \\
(\%)\end{array}$ & $\begin{array}{l}N \\
(\%)\end{array}$ & $\begin{array}{l}D \\
(\%)\end{array}$ & $\begin{array}{l}S D \\
(\%)\end{array}$ \\
\hline The students find easiness to operate Jitsi Meet during their learning. & $14.8 \%$ & $51.9 \%$ & $29.6 \%$ & $3.7 \%$ & $0 \%$ \\
\hline Jitsi Meet helps the students meet their needs in their learning process. & $11.1 \%$ & $33.3 \%$ & $44.4 \%$ & $11.1 \%$ & $0 \%$ \\
\hline Doing interaction through Jitsi Meet is clear and feasible. & $14.8 \%$ & $25.9 \%$ & $44.4 \%$ & $11.1 \%$ & $3.7 \%$ \\
\hline $\begin{array}{l}\text { It is easy to have a class of more than } 50 \text { students on one platform by } \\
\text { using Jitsi Meet. }\end{array}$ & $11.1 \%$ & $51.9 \%$ & $25.9 \%$ & $7.4 \%$ & $3.7 \%$ \\
\hline
\end{tabular}

Table 3: User Attitude

\begin{tabular}{|c|c|c|c|c|c|}
\hline Aspects & $\begin{array}{l}S A \\
(\%)\end{array}$ & $\begin{array}{l}A \\
(\%)\end{array}$ & $\begin{array}{l}N \\
(\%)\end{array}$ & $\begin{array}{l}D \\
(\%)\end{array}$ & $\begin{array}{l}S D \\
(\%)\end{array}$ \\
\hline The students believe that using Jitsi Meet is beneficial. & $7.4 \%$ & $40.7 \%$ & $37 \%$ & $11.1 \%$ & $3.7 \%$ \\
\hline The students believe that Jitsi Meet is a good idea to ease their works. & $18.5 \%$ & $44.4 \%$ & $25.9 \%$ & $11.1 \%$ & $0 \%$ \\
\hline The students feel satisfied by using Jitsi Meet during their learning process. & $7.4 \%$ & $33.3 \%$ & $40.7 \%$ & $18.5 \%$ & $0 \%$ \\
\hline The students feel satisfied while operating Jitsi Meet. & $3.7 \%$ & $40.7 \%$ & $44.4 \%$ & $11.1 \%$ & $0 \%$ \\
\hline The students feel fun while using Jitsi Meet on daily needs. & $0 \%$ & $25.9 \%$ & $44.4 \%$ & $29.6 \%$ & $0 \%$ \\
\hline
\end{tabular}

Table 4: Intense of Use

\begin{tabular}{|c|c|c|c|c|c|}
\hline Aspects & $\begin{array}{l}S A \\
(\%)\end{array}$ & $\begin{array}{l}A \\
(\%)\end{array}$ & $\begin{array}{l}N \\
(\%)\end{array}$ & $\begin{array}{l}D \\
(\%)\end{array}$ & $\begin{array}{l}S D \\
(\%)\end{array}$ \\
\hline Students tend to use Jitsi Meet for their future class. & $3.7 \%$ & $14.8 \%$ & $40.7 \%$ & $37 \%$ & $3.7 \%$ \\
\hline It is recommended to use Jitsi Meet for future needs. & $0 \%$ & $40.7 \%$ & $33.3 \%$ & $25.9 \%$ & $0 \%$ \\
\hline
\end{tabular}


Table 5: The Advantages Toward the Use of Jitsi Meet

\begin{tabular}{|c|c|c|c|c|c|}
\hline Aspects & $\begin{array}{l}S A \\
(\%)\end{array}$ & $\begin{array}{l}A \\
(\%)\end{array}$ & $\begin{array}{l}N \\
(\%)\end{array}$ & $\begin{array}{l}D \\
(\%)\end{array}$ & $\begin{array}{l}S D \\
(\%)\end{array}$ \\
\hline The students have more flexible time to schedule their class. & $25.9 \%$ & $14.8 \%$ & $40.7 \%$ & $18.5 \%$ & $0 \%$ \\
\hline The students do not need to travel to a particular location to have a class. & $0 \%$ & $25.9 \%$ & $44.4 \%$ & $29.6 \%$ & $0 \%$ \\
\hline $\begin{array}{l}\text { The students can save their money during the distance learning because } \\
\text { Jitsi Meet is low-cost. }\end{array}$ & $7.4 \%$ & $22.2 \%$ & $44.4 \%$ & $25.9 \%$ & $0 \%$ \\
\hline The students are interested to learn using Jitsi Meet as their media. & $3.7 \%$ & $29.6 \%$ & $51.9 \%$ & $14.8 \%$ & $0 \%$ \\
\hline $\begin{array}{l}\text { The students get intense interaction and direct feedback during the learning } \\
\text { process. }\end{array}$ & $7.4 \%$ & $55.6 \%$ & $33.3 \%$ & $3.7 \%$ & $0 \%$ \\
\hline
\end{tabular}

inside and outside the classroom. Jitsi Meet may be enhanced by combining it with other applications to increase efficiency.

\section{The Advantages Toward the Use of Jitsi Meet}

Jitsi Meet allows users to hold courses and converse synchronously during distance learning utilizing the videoconferencing system, giving them more freedom in terms of time and location. However, owing to the fact that the distribution of a steady signal in Indonesia is not uniformly distributed based on the geographical characteristics of each location, problems with signal stability continue to be encountered (Harsasi \& Sutawijaya, 2018)

To get a stronger signal, some customers had to move to a higher location. Jitsi Meet also has the benefit of using a small amount of internet bandwidth during the meeting. This is a distinct benefit of Jitsi Meet over other videoconferencing programs that should be emphasized.

When the researcher inquired about users' interest in Jitsi Meet throughout their studies, one reply recommended integrating Jitsi Meet with other programs and employing entertaining techniques to boost student engagement during distant learning. Students can multitask while listening to the lecturer's explanations by utilizing Jitsi Meet as their learning tool-based videoconference system.

There were also ideas for adding a recording function to make it simpler for learners to record all lessons/presentations throughout class so that they could review what they had learned later when they had spare time. Students find it simple to carry out conversations, questions and answers, and direct feedback either verbally or textually utilizing Jitsi Meet's function.

As a result, using Jitsi Meet in the learning process provides several benefits in line with Gillies (2008) with regards to the video conferencing system When comparing Jitsi Meet to other videoconferences, this might be a selling factor. However, the approach used to optimize Jitsi Meet as a learning medium is dependent on the technique.

\section{CONCLUSION}

Students had a good view of Jitsi Meet as a learning tool in the EFL classroom, according to the findings. They claim that
Jitsi Meet is a useful video conferencing technology, especially for distant learning. Because capabilities like share screen, microphone, and chatroom make it simple for students to communicate with colleagues and lecturers at the same time, Jitsi Meet is the ideal choice for becoming a tool in meetings or discussions both inside and outside the classroom. This feature is quite useful in preventing misunderstanding. Another result of using this technology is that some learners who are passive in offline courses behave differently in online sessions. Some learners would like to use Jitsi Meet in the future. This is owing to the convenience offered, which includes time and location flexibility. Jitsi Meet also consumes less internet bandwidth, allowing it to save money. Some students also reported that they were able to multitask while listening to the lecturer's explanations in class. This means that Jitsi Meet may be enhanced with additional apps to create a new learning environment.

However, there are a few aspects that could be improved, like the stability of the internet signal and the server from Jitsi Meet. Additionally, students would benefit from the addition of additional features such as the recording capability, which would allow students to examine the lecturer's explanation of course material. Another point to emphasize in this study is the developer's lack of marketing and constant information, which has resulted in relatively few users of this program, even on the internal campus.

\section{References}

Al-Maroof, R. A. S., \& Al-Emran, M. (2018). Students acceptance of google classroom: An exploratory study using PLS-SEM approach. International Journal of Emerging Technologies in Learning, 13(6), 112-123. https://doi.org/10.3991/ijet.v13i06.8275

Basko, L., \& Hartman, J. (2017). Increasing Student Engagement Through Paired Technologies. Journal of Instructional Research, 6(1), 24-28. https://doi.org/10.9743/jir.2017.4

Blasco, M. F., \& Virto, L. N. R. (2020). E-learning using Video Conferencing Applications: How is Google Meet perceived among students?

Davis, F. D. (1989). Perceived usefulness, perceived ease of use, and user acceptance of information technology. MIS Quarterly: Management Information Systems. https://doi. $\operatorname{org} / 10.2307 / 249008$ 
Genc Ilter, B. (2009). Effect of technology on motivation in EFL classrooms. Turkish Online Journal of Distance Education, 10(4), 136-158. https://doi.org/10.17718/tojde.37730

Gillies, D. (2008). Student perspectives on videoconferencing in teacher education at a distance. Distance Education, 29(1), 107-118. https://doi.org/10.1080/01587910802004 878

Harsasi, M., \& Sutawijaya, A. (2018). Determinants of student satisfaction in online tutorial: A study of a distance education institution. Turkish Online Journal of Distance Education, 19(1), 89-99. https://doi.org/10.17718/tojde.382732

Karal, H., Çebi, A., \& Turgut, Y. E. (2011). Perceptions of students who take synchronous courses through video conferencing about distance education. Turkish Online Journal of Educational Technology, 10(4), 276-293.
Martin, M. (2005). Seeing is believing: The role of videoconferencing in distance learning. British Journal of Educational Technology, 36(3), 397-405. https://doi.org/10.1111/j.1467-8535.2005.00471.x

Masrom, M. (2007). Technology acceptance model and E-learning. 12th International Conference on Education, May, 21-24.

Miles, B. M., \& Huberman, A. M. (1994). Qualitative Data Analysis An expanded Sourcebook 2nd Edition (R. Holland (ed.); 2nd ed.). SAGE Publications.

Park, Y., \& Bonk, C. (2007). Is online life a breeze? A case study for promoting synchronous learning in a blended graduate course. Journal of Online Learning and Teachingg, 3(3), 307-323. http:// jolt.merlot.org/vol3no3/park.htm

Sefrika, \& Alawiah, T.E. (2020). Acceptance of Video Conference Technology as a Distance Learning Media with the TAM Method. International Journal of Information System \& Technology, 4(36), 465-470. 